\title{
Removal of Some Heavy Metals from Incinerator Bottom Ash Using Coconut (Cocos Nucifera) Husk
}

\author{
Doris F. Ogeleka ${ }^{1}$, Harrison E. Avrukpere ${ }^{1}$, Elias E. Elemike ${ }^{1}$, Oghenekohwiroro Edjere ${ }^{2}$, Iwekumo E. Agbozu ${ }^{2}$ \\ ${ }^{1}$ Department of Chemistry, Federal University of Petroleum Resources, Effurun, Delta State, Nigeria \\ ${ }^{2}$ Department of Environmental Management and Toxicology, Federal University of Petroleum Resources, Effurun, \\ Delta State, Nigeria \\ Correspondence: Doris F. Ogeleka, Department of Chemistry, Federal University of Petroleum Resources, Effurun, \\ Delta State, Nigeria. E-mail: dorysafam@yahoo.com
}

Received: May 12, 2016 Accepted: May 30, 2016 Online Published: September 28, 2016

doi:10.5539/ijc.v8n4p69

URL: http://dx.doi.org/10.5539/ijc.v8n4p69

\begin{abstract}
There has been a great limitation to the use of incinerator bottom ash (IBA) residue in the construction and manufacturing industries due to the high contents of heavy metals, which poses great threat to the environment and human health. This study was carried out to evaluate the efficiency of heavy metals ( $\mathrm{Fe}, \mathrm{Zn}, \mathrm{Cd}$ and $\mathrm{Pb}$ ) removal from domestic IBA filtrate using a biological material coconut (Cocos nucifera) husk as adsorbent and to remove the metals from the ash residue using the toxicity characteristic leaching procedure (TCLP). The mean percentage removal of the heavy metals for the incinerator bottom ash (IBA) filtrate varied from $75.84-99.42 \%$ for the two ash types. Similarly, the percentage removal of metals from the ash residues was between 92.34 and $99.97 \%$. The data from this study showed that after the treatment, the heavy metals in the ash filtrate and residue were significantly reduced. Thus, it would be feasible to use the IBA residue as a partial replacement of cement in the construction and manufacturing industries for making monolithic blocks, interlocking bricks, concretes and road construction materials. This would help improve and provide good and effective waste management practice that would reduce the huge volume of ash residue from incineration combustion processes.
\end{abstract}

Keywords: incinerator bottom ash, waste management \& utilization, adsorption, hazardous and domestic waste, TCLP, heavy metals

\section{Introduction}

Incineration is one of the major techniques for managing solid wastes in some developed and developing nations since it reduces the volume of waste by 80 to $90 \%$. Municipal solid waste (MSW) consists of everyday items we use and dispose such as product packaging, furniture, clothing, bottles, food scraps, newspapers, appliances, paint, batteries etc. These wastes which come from homes, schools, hospitals, and businesses could cause detrimental effects on environmental media if not properly managed or disposed (EPA, 1980; El-Haggar, 2007). Depending on the municipality, solid waste could be managed using the four R's of waste management namely reduce, reuse, recycle and recover, however, incineration could be used for the final disposal of various types of waste. As waste generation rate increases, incineration processing costs increases, and available landfill space decreases, thus, the four R's have become a central tenet in sustainable waste management efforts (Seadon, 2006; Davis, 2008; Suttibak \& Nitivattananon, 2008; Tudor et al., 2011). Some techniques commonly used for the treatment or management of waste in addition to incineration include: landfill/ engineered landfill, compositing, mechanical biological treatment (MBT), pyrolysis and gasification, detoxifying hazardous waste, thermal desorption unit (TDU), etc.

Generally, solid waste incineration produces two main types of ash, which can be grouped as incinerator bottom ash (IBA), which are solid waste that are not completely burned on the grate and incinerator fly ash (IFA), which are solid and condensable particulate matter which leaves the furnace suspended in the combustion gases and are subsequently collected in emission control devices. The waste (ash) generated from incineration, usually ends up in two ways; disposal in landfill or reuse as secondary raw materials. In most developed countries where land is scarce and environmental controls are enforced, environmental policies tend to reduce landfill disposals as much as possible (Lam et al., 2010).

The ash residues produced from the burning of wastes could be used commercially as raw material in cosmetics 
production including soap making. It could also be used as partial replacement for cement in many manufacturing and construction industries in making noise barriers, capping layer on landfill sites and as aggregate in asphalt. However, this use is limited due to the presence of some contaminants in the ash, as a result of the chemical and physical characterization of the ash residues, which depend on the compositions of the raw waste, type of incinerator used and incineration process ( $\mathrm{Li}$ et al., 2004).The incineration bottom ash (IBA) is the most significant by-product from incineration as it accounts for $85-95 \%$ product resulting from combustion. It is important to note that the metals in the wastes are not destroyed during the incineration process and may pose harmful environmental consequences and health problems if not properly treated or managed (Ogwuegbu et al., 2007). Much of the exposure to heavy metal pollution has been scientifically proven to be linked to causing free radical damage leading to heart attacks, cardiovascular disease, high blood pressure, strokes, cancer and many more. In environmental premises, bioavailability of these metals could lead to respiratory problem, growth impairment, reproduction defect as well as disruption of the ability of the organism to fight disease and function (Saleh, 1982).

Over the last few decades, several methods have been devised for the treatment and removal of heavy metals from contaminated materials. The commonly used procedures for removing metal ions from aqueous streams include; adsorption, ion exchange, biosorption, filter traps, electrodeposition and chemical precipitation (Rich \& Cherry, 1987). The method adopted for this research is adsorption, which is a process through which a substance, originally present in one phase, is removed from that phase by accumulation at the interface between that phase and a separate (solid) phase (Jalal et al., 2002; Agbozu \& Emoruwa, 2014).The contaminants commonly found in the bottom ash which contribute adversely to the environment and human health and were considered in this study include zinc, iron, lead and cadmium. The objective of this study was to evaluate the removal of these contaminants from the incinerator bottom ash liquid extract (leachate) using coconut (Cocos nucifera) husk and from the ash residue using the toxicity characteristic leaching procedure (TCLP).

\section{Materials and Method}

\subsection{Study Area}

The selected point of sampling lies between $5^{\circ} 31^{\prime} \mathrm{N}$ and $5^{\circ} 45^{\prime} \mathrm{E}$, Warri, a City in the Niger Delta ecological zone of Delta State, Nigeria (Figure 1). It is an oil hub in southern Nigeria and experiences moderate rainfall and moderate humidity for most part of the year. The area is characterized by tropical equatorial climate with mean annual temperature of $32.8{ }^{\circ} \mathrm{C}$ and rainfall between $3000-4500 \mathrm{~mm}$ (Tamuno, 2000; Balouga, 2009). It is one of the major hubs of petroleum activities whose waste management practices involve the use of open dump sites for public utility while incineration and thermal desorption unit are used mainly by some specific Oil Exploration and Production (E\&P) companies (Ekeh, 2005).

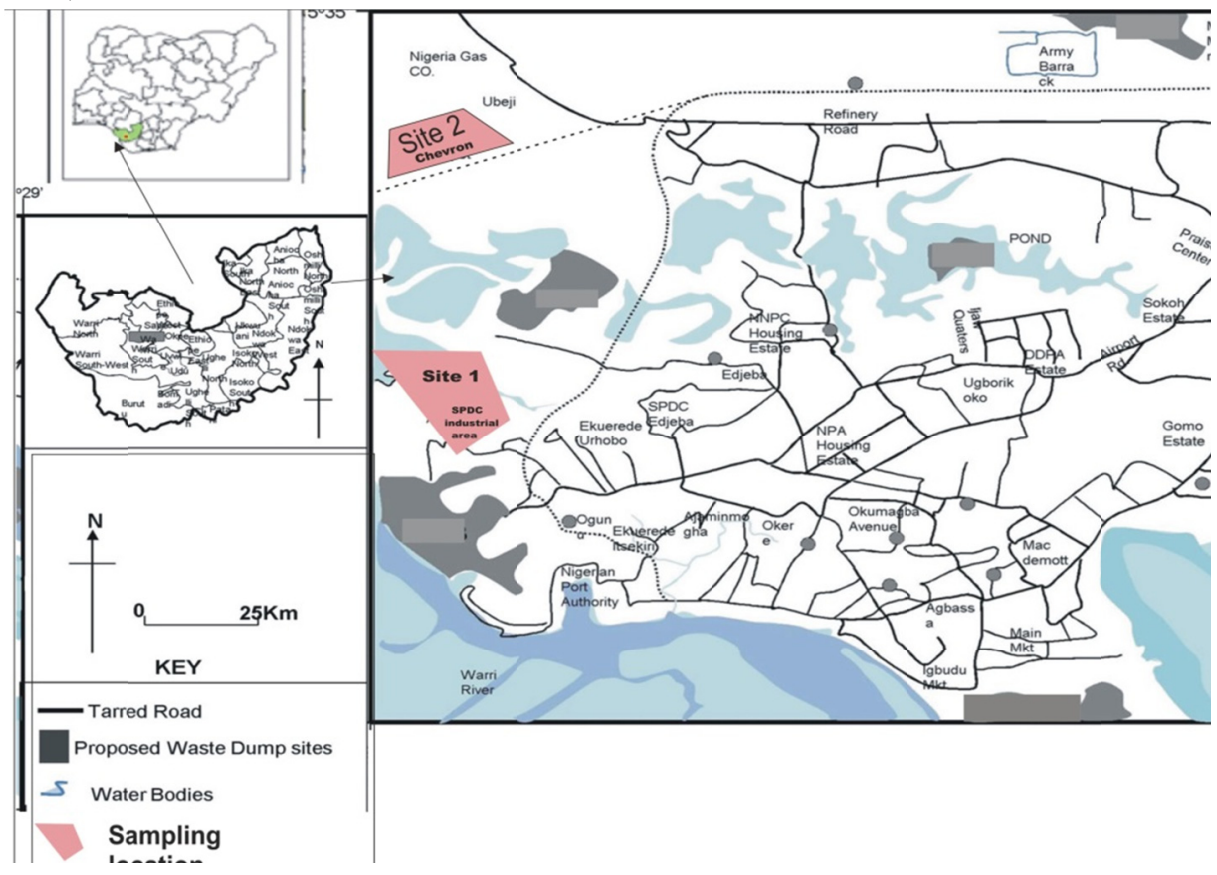

Figure 1. Map of sampling location in Warri, Delta state 


\subsection{Ash Sampling}

The incinerator bottom ash (IBA) was collected from the waste management unit of two oil Exploration and Production (E\&P) companies. Twenty four (24) samples were randomly collected in triplicate and stored for analysis. The waste types used in this study include: domestic waste ash (DW) - obtained through the incineration of domestic waste other than hazardous waste and hazardous waste ash (HW) - obtained through the incineration of medical waste, other biological and hazardous waste. These ash wastes would subsequently be referred to as ash A for domestic waste (DW) and ash B for hazardous waste (HW).

\subsection{Bio-adsorbent Sampling and Treatment}

Coconut (Cocos nucifera) husk was collected and sun dried for approximately seven (7) days and ground into fine particles and sieved to obtain $120 \mu \mathrm{m}$ (micrometer mesh). The particles were treated with $0.1 \mathrm{M} \mathrm{HCl}$ and re-introduced into an oven at a temperature of $30^{\circ} \mathrm{C}$ for 30 minutes and then preserved for further use.

\subsection{Extraction and Determination of Metals in Ash Residue Using TCLP}

Five (5) $\mathrm{g}$ of the crushed ash sample was accurately weighed into a sample extraction bottle and $96.5 \mathrm{~mL}$ of distilled water was added. This was covered with a watch glass and stirred vigorously for 5 minutes and the $\mathrm{pH}$ and electrical conductivity was determined. From the guidelines of EPA - SW-846 \#1311 and DPR (EPA, 1992; DPR, 2011), extraction solution $\# 2$ was used for the metal extraction in the ash sample because the $\mathrm{pH}$ of the solution was greater than 5. If otherwise (i.e. $<5$ ), extraction fluid \#1 would have been used. Extraction fluid \#1 was prepared by accurately measuring $5.7 \mathrm{~mL}$ glacial acetic acid, to which $500 \mathrm{~mL}$ of distilled water and $64.3 \mathrm{~mL}$ of $1 \mathrm{M} \mathrm{NaOH}$ was added and diluted to a volume of 1 litre. Extraction fluid $\# 2$ was prepared by accurately measuring $5.7 \mathrm{~mL}$ glacial acetic acid and added to distilled water make up to a volume of 1 litre.

For the metal extraction, $200 \mathrm{~mL}$ of extracting solution was added to $10 \mathrm{~g}$ of the crushed ash residue sample. This solution was shaken first for 2 minutes by hand to ensure saturation of the solid with the solution. Then the flask was shaken with an oscillator for 16 hours to ensure full saturation of the solid with the solution. The resultant slurry was centrifuged at $2000 \mathrm{rpm}$ and the supernatant was carefully decanted through a glass funnel and the filtrate stored. This process was repeated three (3) times and the filtrate stored for the adsorption procedure while the concentration of heavy metals in the residues was determined using atomic absorption spectrophotometer.

\subsection{Elution and Determination of Metals in Ash Filtrate}

Ten (10) g powder of the pre-treated biological material - coconut (Cocos nucifera) husk was packed in a column stoppered at the tip with glass wool and $50 \mathrm{~mL}$ of the washed ash filtrate from the extraction of the residue introduced, allowed to drain through the packed column and repeated three times. The time taken for elution was recorded with a stop watch. Fifty (50) $\mathrm{mL}$ of the resultant eluate was digested using $5 \mathrm{~mL}$ concentrated nitric acid (AR). This reduced to the lowest volume possible ( 15 to $20 \mathrm{~mL}$ ). Filtration was done after digestion to remove any insoluble material. The filtrate was then diluted to volume with distilled water in a $50 \mathrm{~mL}$ volumetric flask (APHA, 2005). The concentration of the heavy metals was analyzed using Atomic Absorption Spectrophotometer (AAS) by direct aspiration into a standardized computer interfaced with the instrument.

\section{Results}

The results obtained from the heavy metals analysis carried out on incinerator bottom ash are presented in Tables 1 and 2 with further illustrations in Figure 2-8. The tables indicate the concentration of heavy metals in the incinerator bottom ash filtrate before and after treatment with coconut husk as well as the extraction of metals from the ash residue.

Table 1. Mean percentage metal removal from ash filtrate

\begin{tabular}{lllllll}
\hline $\begin{array}{l}\text { Parameters } \\
(\mathrm{mg} / \mathrm{L})\end{array}$ & Untreated & Treated & \% removal & Untreated & Treated & \% removal \\
\hline & Ash A & Ash A & Ash A & Ash B & Ash B & Ash B \\
Iron & $5.118 \pm 0.05$ & $1.236 \pm 0.007$ & $75.84 \pm 0.03 \%$ & $6.403 \pm 0.09$ & $1.132 \pm 0.010$ & $82.32 \pm 0.06 \%$ \\
Zinc & $3.152 \pm 0.03$ & $0.030 \pm 0.005$ & $99.05 \pm 0.06 \%$ & $4.106 \pm 0.06$ & $0.024 \pm 0.002$ & $99.42 \pm 0.08 \%$ \\
Cadmium & $1.046 \pm 0.008$ & $0.021 \pm 0.004$ & $97.99 \pm 0.05 \%$ & $0.092 \pm 0.005$ & $0.011 \pm 0.001$ & $88.04 \pm 0.03 \%$ \\
Lead & $<0.001$ & $<0.001$ & - & $<0.001$ & $<0.001$ & - \\
\hline
\end{tabular}

The washing of the ash resulted in filtrate, which was bio-treated using coconut husk and resulted in a decrease in the metal concentrations (Table 1). There was significant difference at levels of $P<0.05$ between concentration obtained before and after adsorption (Figure 2-3). Although ash B contained slightly a higher magnitude of metals than ash A, this could be as a result of the constituent of the hazardous waste, which comprises mainly of medical waste (syringes, needles, blades, forceps, and other related bio-medical waste) which was not destroyed in the incinerated residues. 


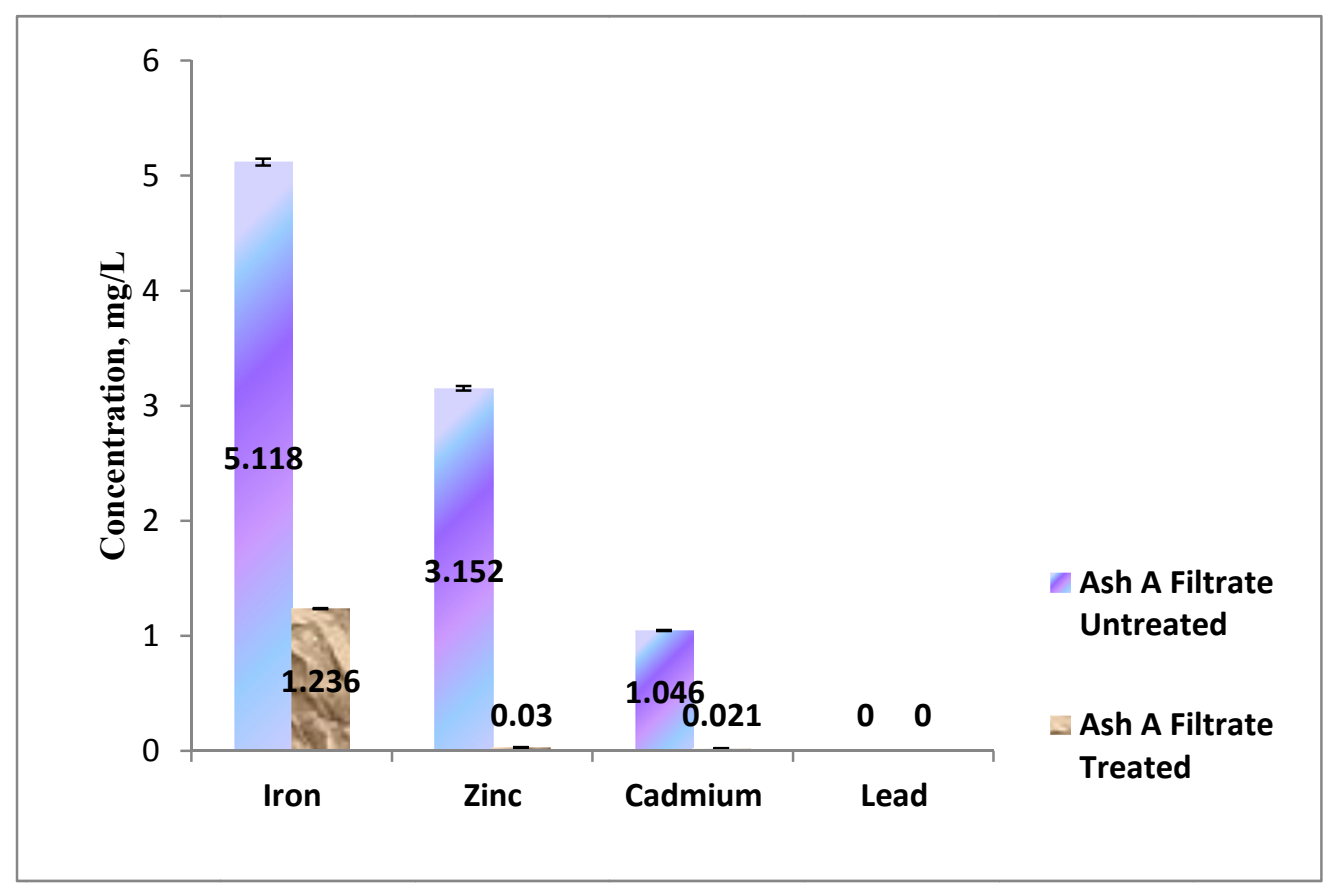

Figure 2. Mean $\pm \mathrm{SEM}$ of Ash A filtrate before and after adsorption

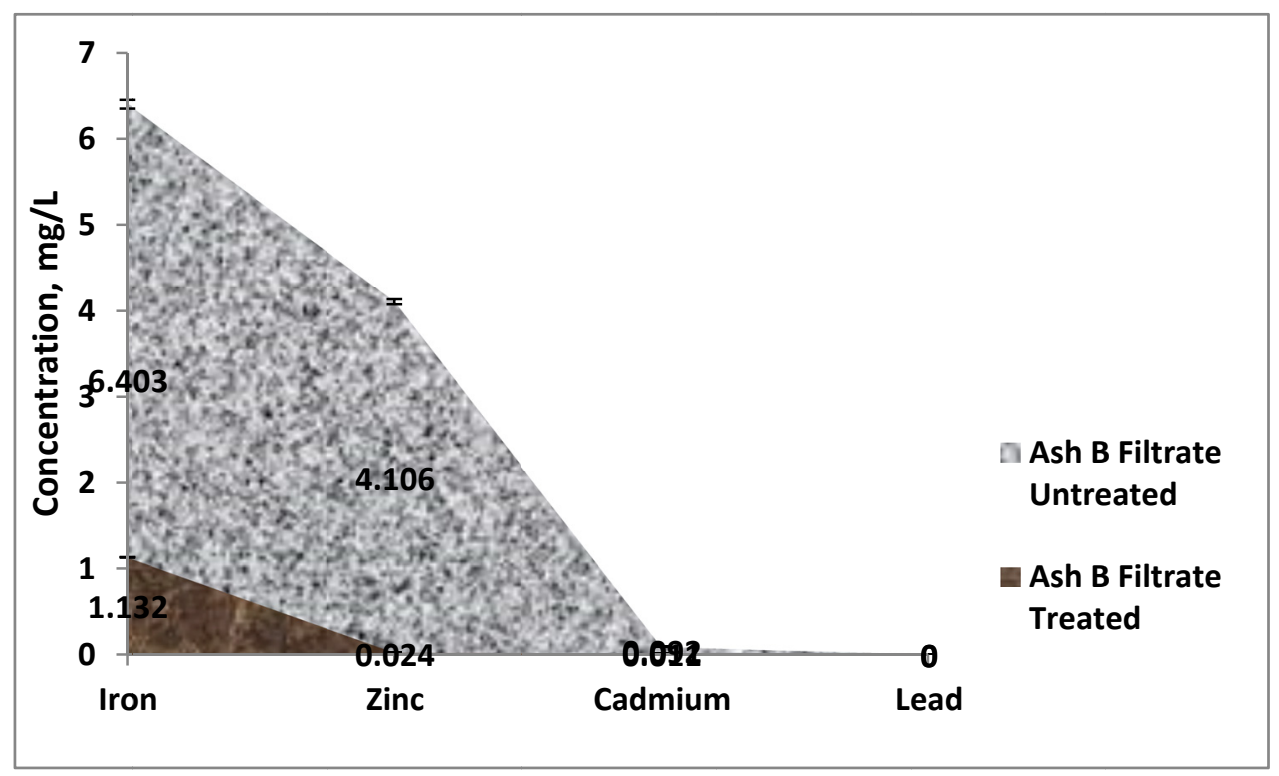

Figure 3. Mean \pm SEM of Ash B filtrate before and after adsorption

The average percentage removal of heavy metals after treatment for the two ash samples resulted in a range of 75.84 $99.05 \%$ and $82.32-99.42 \%$ for ash A and B respectively (Figure 4). 


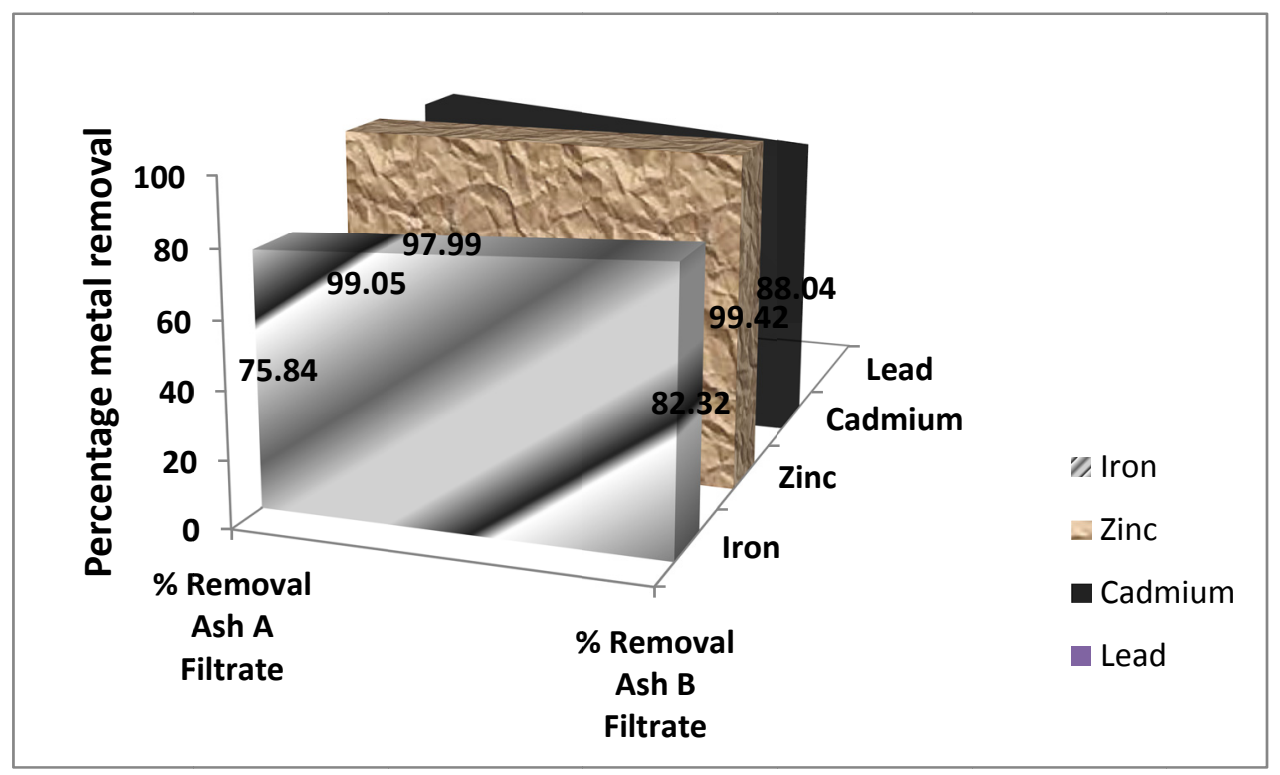

Figure 4. Mean \% metal removal in Ash A and B filtrate

There was slight variation between the two ash samples in terms of percentage metal removal.

Table 2. Mean percentage metal removal from ash residue

\begin{tabular}{lccccccc}
\hline $\begin{array}{l}\text { Parameter, } \\
(\mathbf{m g} / \mathbf{k g})\end{array}$ & $\begin{array}{c}\text { DPR } \\
\text { Limits }\end{array}$ & $\begin{array}{c}\text { Before } \\
\text { extraction }\end{array}$ & $\begin{array}{c}\text { After } \\
\text { extraction }\end{array}$ & \% removal & $\begin{array}{c}\text { Before } \\
\text { extraction }\end{array}$ & $\begin{array}{c}\text { After } \\
\text { extraction }\end{array}$ & \% removal \\
\hline & & Ash A & Ash A & Ash A & Ash B & Ash B & Ash B \\
\hline Iron & N/A & $175.340 \pm 0.9$ & $2.056 \pm 0.05$ & $98.83 \pm 0.05 \%$ & $181.280 \pm 0.11$ & $2.965 \pm 0.06$ & $98.36 \pm 0.04 \%$ \\
Zinc & 50.00 & $20.576 \pm 0.34$ & $1.576 \pm 0.007$ & $92.34 \pm 0.04 \%$ & $16.756 \pm 0.56$ & $0.524 \pm 0.009$ & $96.87 \pm 0.06 \%$ \\
Cadmium & 1.00 & $0.187 \pm 0.005$ & $<0.001$ & $99.97 \pm 0.08 \%$ & $0.237 \pm 0.008$ & $<0.001$ & $99.97 \pm 0.09 \%$ \\
Lead & 5.00 & $4.575 \pm 0.08$ & $0.001 \pm 0.001$ & $99.95 \pm 0.07 \%$ & $4.845 \pm 0.06$ & $0.001 \pm 0.001$ & $99.95 \pm 0.08 \%$ \\
\hline
\end{tabular}

$\mathrm{N} / \mathrm{A}=$ Not available

The ash residues contained some quantity of heavy metals before extraction, although the levels of zinc, cadmium, and lead were within the DPR stipulated limits of $50.00 \mathrm{mg} / \mathrm{kg}, 1.00 \mathrm{mg} / \mathrm{kg}, 5.00 \mathrm{mg} / \mathrm{kg}$ respectively. However, the concentrations in the ash residues were significantly reduced after extraction (Table 2). The levels of significance before and after extraction was at $P<0.05$ (Figures 5 and 6).

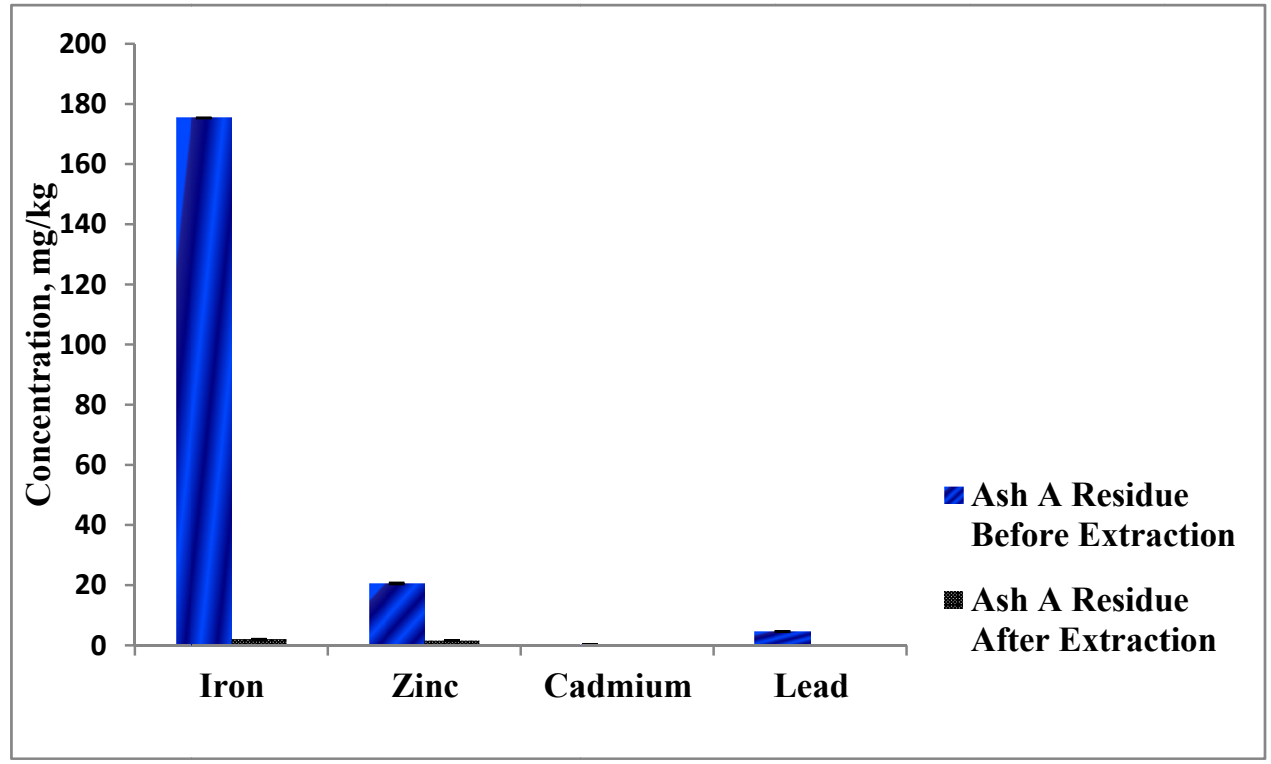

Figure 5. Mean \pm SEM of Ash A residue before and after extraction 


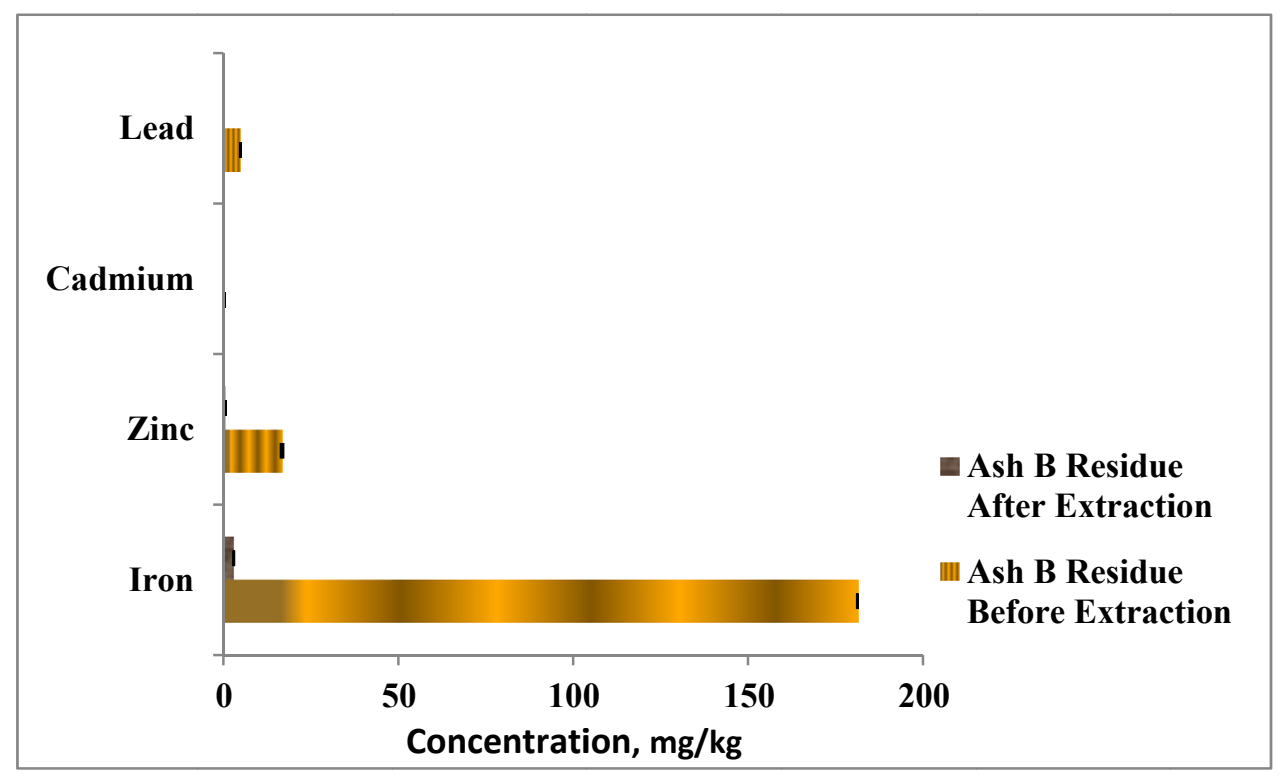

Figure 6. Mean $\pm \mathrm{SEM}$ of Ash B residue before and after extraction

The percentage of the heavy metals removed after washing of ash A and B was 92.34-99.97 and 96.87-99.97 respectively (Figure 7).

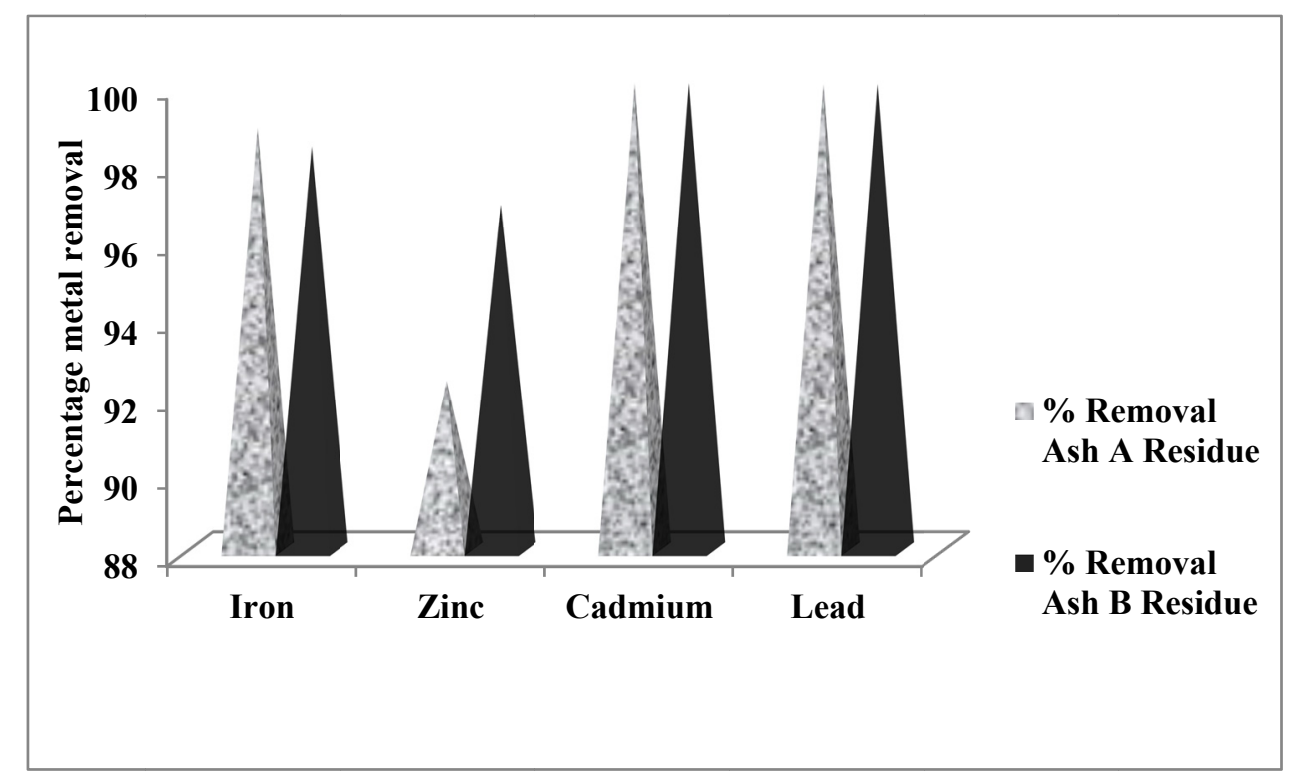

Figure 7. Mean \% metal removal in Ash A and B residue

A significant $\%(>90 \%)$ of metal was removed from the ash residue in the two ash types. However, the magnitude in variation between the two ash samples was slight except for zinc.

The $\mathrm{pH}$ and electrical conductivity values recorded for ash $\mathrm{A}$ and $\mathrm{B}$ was $10.76,9.71$ and 8.92 and $7.94 \mathrm{mS} / \mathrm{cm}$ respectively. The values for ash A was in higher magnitude than their corresponding DPR limits for $\mathrm{pH}(6.50-9.00)$ and electrical conductivity (8.00) (Figure 8). 


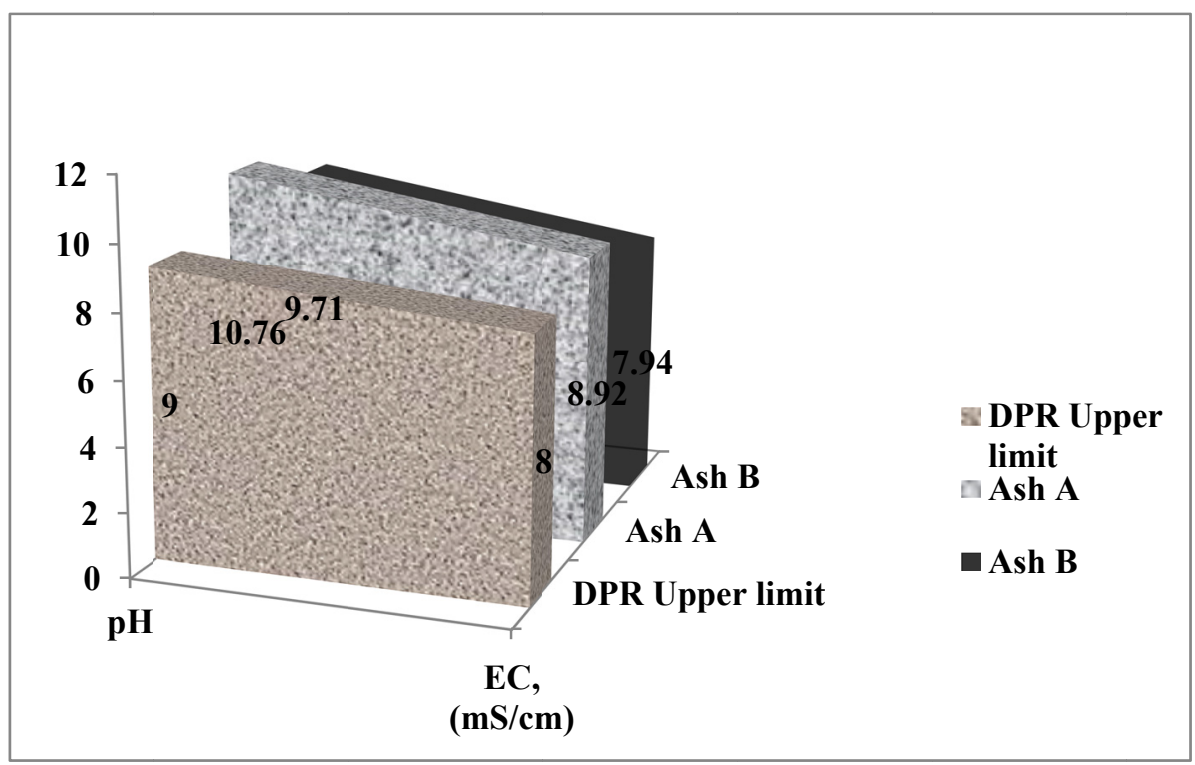

Figure 8. pH and Electrical conductivity in comparison with DPR limits

\section{Discussion}

\subsection{Efficiency of Metal Removal from Ash Residue}

The TCLP test using the EPA procedure of SW-846 method \#1311 and the DPR protocol was to determine the mobility of metals and toxicants in the ash residue. The leaching test had been recognized as the primary and most widely used indicator for evaluating the retention capacity of toxicant in solid waste samples. The method is the process by which inorganic, organic contaminants or radionuclides are released from the solid phase into the liquid phase under the influence of mineral dissolution, desorption, complexation process as affected by the pH (EPA, 1992; DPR, 2011; Singh and Gadi, 2012).

The study evaluated the percentage of the metals that was leached out of the ash residue since the incinerator ash leftover/residue is considered toxic due to the fact that it still contained an appreciable amount of lead, cadmium, iron, zinc and other heavy metals. Thus, the binding capacity of substances in the solid matrix at high $\mathrm{pH}$ levels could be quite high and would not be expected to leach into underground or surface water except the $\mathrm{pH}$ of rain water or contact water of that of the environment falls below $3 \mathrm{pH}$ units, which could cause dissolution of metals and allow them to be released from the solid matrix.

Moreover, if the incinerator ash is left untreated before being used as a raw material for construction and manufacture purposes, leaching would be highly detrimental to various forms of lives in the environment and human health due to the high heavy metal content that would be bio-available at very low $\mathrm{pH}(2-3)$ since the metals are not destroyed during the incineration process (Baby et al., 2010). Meeting regulatory limits is a standard consideration for ensuring that the ash waste are not released at levels that can harm aquatic and terrestrial organisms as well as man being the end user or consumer of the organisms in the environment.

However, the heavy metals evaluated in this research showed relatively low concentrations after the TCLP treatment method and would not be expected to leach and affect the environment (surface, ground water, soil and sediment).That is the mobility of pollutant would be very minimal and may not likely impact environmental media if the ash residues are solidified/stabilized as bricks/concrete (Okieimen \& Onyenkpa, 2000; Jalal et al., 2002). The treatment would make the incinerator ash feasible to use for construction and manufacturing purposes as well as enhance proper and best waste management practice. However, since metals are bound effectively within the solidified waste matrix, the potential of converting a solidified ash waste to bricks and tiles for pavement, parking lots and paths or even for road construction would be highly exploited.

\subsection{Efficiency of Metal Removal from Ash Filtrate}

The susceptibility of $\mathrm{pH}$ could be linked to the nature of the ions in the filtrate and the adsorbent used. Similarly, the nature of the hydrogen ion concentration in solution is also as a result of the component that constitutes the ash sample, thus creating more sites for the adsorption process. Increase in concentration of the adsorbate brings about increase in competition of adsorbate molecules for few available binding sites on the surface of the adsorbent, hence, increase in the amount of metal ions removed. These results are in accordance with the work of Okieimen \& Onyenkpa, (2000). 
The percentage removal of heavy metal was due to the greater availability of the exchangeable sites and surface area of the adsorbent. The coconut husk was adequately treated to remove traces of heavy metals that would interfere or cause contamination of the process. The removal of metal ion from the ash filtrates was effective since the bio-material was able to release an appreciate level of the metals present in the solution. The percentage heavy metal removal obtained from treating the two ash samples with the biological material (coconut husk), indicated that it is a safe and cheap material for the treatment of the incinerator bottom ash filtrates / solutions (Abdel-Ghani \& El-Chaghaby, 2009).

The use of the cellulosic biological waste material as an adsorbent in treatment of incinerator bottom ash filtrate and the TCLP method of metal removal from solid ash waste would go a long way in solving environmental pollution problems that seems to be intractable to the society. The results and findings of this study are in agreement with previous studies made on heavy metal removal using coconut husk as an adsorbent (Agbozu \& Emoruwa, 2014).

\section{Conclusion}

We conclude that cellulosic biological waste (e.g. coconut husk) was a good adsorbent for the removal of heavy metals from incinerator bottom ash filtrate and solution. Similarly, the TCLP method was effective in the removal of some major heavy metal contaminants in the incinerator bottom ash (IBA) residues, thus, enhancing the chances of using it in construction industries for making monolithic blocks, interlocking bricks, concretes and other road construction materials. Thus, effective removal of the contaminants from the ash residue could also mean an environmentally safe and convenient use of the raw material in cosmetics production including soap making, road construction, as foundation material, in noise barriers, as capping layer on landfill sites and in some countries as an aggregate in asphalt etc.

\section{References}

Abdel-Ghani, N. T., \& El-Chaghaby, G. A. (2009). Simultaneous removal of chromium, copper, cadmium and lead ions from aqueous solution by adsorption onto kaolin. Int. J. Geotechnics Environ, 1(2), 161-171.

Agbozu, I. E., \& Emoruwa, F. O. (2014). Batch adsorption of heavy metals (Cu, Pb, Fe, Cr, and $\mathrm{Cd})$ from aqueous solutions using coconut husk. African Journal of Environmental Science and Technology, 8(4), 240-246.

American Public Health Association APHA, America Water Works Association. AWWA, Water Environmental Federation WEF. (2005). Standard methods for the examination of water and wastewater. 21st ed.

Baby, J., Raj, J. S., Biby, E. T., Sankarganesh, P., Jeevitha, M. V., \& Ajisha, S. U. (2010). Toxic effect of heavy metals on aquatic environment. Int. J. Biol. Chem. Sci., 4(4), 939-952.

Balouga, J. (2009). The Niger Delta: Defusing the time bomb. International Association for Energy Economics, 1, 8-11.

Davis, U. C. (2008). The 4 R's of waste reduction: Waste management. Academic Journal, 40, 13-17.

Department of Petroleum Resources (DPR) (2011).Environment Guidelines and Standards for the Petroleum Industry in Nigeria (EGASPIN) Revised Edition.

Ekeh, P. P. (2005). Warri City and British colonial rule in Western Niger Delta. Urhobo Historical Society, 31.

El-Haggar, S. M. (2007). Sustainable industrial design and waste management: Cradle-to-cradle for sustainable development. Oxford: Elsevier/Academic Press. 424.

Environmental Protection Agency (EPA). (1980). Environmental fact sheet, [EPA/530-SW-90-029c]: Characterization of municipal waste combustion ash, ash extracts, and leachates. Springfield, Va. 22161.

Environmental Protection Agency (EPA).(1992). Test methods for evaluating solid wastes (SW 846), physical and chemical methods. Method 1311, toxicity characteristic leaching procedure (TCLP), Environmental Protection Agency, Washington, DC, 1-38.

Jalal, R., Bhajourian, H., Asif, Y., Davarpanash, S. J., \& Sepher, S. (2002). Removal and recovery of lead using nonliving biomass of algae. J. Hazardous Mater, 24, 421-430. http://dx.doi.org/10.1016/s0304-3894(02)00021-3

Lam, C. H. K., Ip, A. W. M., Barford, J. P., \& McKay, G. (2010). Use of incineration MSW ash: A Review. Sustainability, 2, 1943-1968. http://dx.doi.org/10.3390/su2071943

Li, M., Xiang, J., Hu, S., Sun, L. S., Su, S., Li, P. S., \& Sun, X. X. (2004). Characterization of solid residues from municipal solid waste incinerator. Fuel, 83, 1397-1405. http://dx.doi.org/10.1016/j.fuel.2004.01.005

Ogwuegbu, M. O. C., Egwurugwu, J. N., \& Duruibe, J. O. (2007). Heavy metal pollution and human biotoxic effect. Int. J. of Physics Sciences, 2, 112.

Okieimen, F. E., \& Onyenkpa, V. U. (2000). Binding of cadmium, copper, lead and nickel ions with melon (Citrullus vulgaris) seed husk. Biol. Waste, 29, 11-16. http://dx.doi.org/10.1016/0269-7483(89)90099-2 
Rich, G., \& Cherry, K. (1987). Hazardous waste treatment technologies. Pudram Publ. Co., 169.

Saleh, H. H. (1982). Fish liver as an indicator for aquatic environmental pollution. Bull. Inst.Oceanogr. and Fish. 8(1), 69-79.

Seadon, J. K. (2006). Integrated waste management: looking beyond the solid waste horizon. Waste management, 26(12), 1327-1336. http://dx.doi.org/10.1016/j.wasman.2006.04.009

Singh, N., \& Gadi, R. (2012). Bioremediation of $\mathrm{Ni}(\mathrm{II})$ and $\mathrm{Cu}(\mathrm{II})$ from wastewater by the nonliving biomass of Brevundimonas vesicularis .Journal of Environmental Chemistry and Ecotoxicology, 4(8), 137-142.

Suttibak, S., \& Nitivattananon, V. (2008). Resources, conservation and recycling assessment of factors influencing the performance of solid waste recycling programs. Conservation and Recycling, 53, 45-56.

http://dx.doi.org/10.1016/j.resconrec.2008.09.004

Tamuno, T. (2000).The Niger Delta question, Port Harcourt: Riverside Communications. Tell Magazine. (2005). 18 April, 16-18.

Tudor, T., Robinson, G., Riley, M., Guilbert, S., \& Barr, S. (2011). Challenges facing the sustainable consumption and waste management agendas. Local Environment, 16(1), 51-66. http://dx.doi.org/10.1080/13549839.2010.548372

\section{Copyrights}

Copyright for this article is retained by the author(s), with first publication rights granted to the journal.

This is an open-access article distributed under the terms and conditions of the Creative Commons Attribution license (http://creativecommons.org/licenses/by/4.0/). 